\title{
Effect of Habitat Type and Population Density on the Stress Level of Midday Gerbils (Meriones meridianus Pall.) in Free-Living Populations
}

\author{
V. A. Kuznetsov*, A. V. Tchabovsky**, I. E. Kolosova***, and M. P. Moshkin*** \\ * Biological Faculty, Moscow State University, Vorob'evy Gory, Moscow, 119899 Russia \\ e-mail: kuznetsov@biodiversity.ru \\ ** Severtsov Institute of Ecology and Evolution, Russian Academy of Sciences, Leninskii pr. 33, Moscow, 117071 Russia \\ e-mail:a.sadov@relcom.ru \\ *** Institute of Animal Systematics and Ecology, Siberian Division, Russian Academy of Sciences, ul. Frunze 11, Novosibirsk, \\ 630091 Russia \\ e-mail:mmp@eco.nsc.ru \\ Received March 27, 2004
}

\begin{abstract}
New methods of noninvasive evaluation of the endocrine status of animals by the content of hormones in their feces were used to study the relationship between the stress level and social (population density) and ecological (habitat integrity) indices in natural populations of midday gerbil in the Southern Kalmykia in 2000. Stress level proved to increase with habitat disturbance but did not depend on population density of animals. The obtained data are discussed in the context of species-specific ecology and social behavior of midday gerbils.
\end{abstract}

\section{INTRODUCTION}

The notion of the relationship between the level of aggressive interactions, activation of physiological systems of stress, and reproduction rate were introduced by Christian (1950) as a possible mechanism of density-dependent limit of population growth. Later it promoted numerous field and laboratory studies reviewed elsewhere (Christian and Davis, 1966; Shilov, 1977; Boonstra, 1998). These studies demonstrated that the positive correlation between population density and the stress level postulated by the Christian's hypothesis is not always observed (Evsikov and Moshkin, 1994). Even in different populations of the same species, oscillations of functional activity of the adrenal cortex (as a marker of stress) can match or mismatch animal population dynamics, which is partially due to the requirement for reaching the threshold density triggering the automatic control of reproduction (Evsikov and Moshkin, 1994; Novikov and Moshkin, 1998). In addition, the pattern of involvement of stress mechanisms in formation of demographic and spatial-ethological structure of populations has species-specific distinctions resulting from specific behavior and morphophysiological organization (Popov and Tchabovsky, 1995; Hennessy, 1999).

Comparative studies of the endocrine control of population processes has made considerable progress in the recent decade due to the development of noninvasive assays for stress hormones (Gerlinskaya, 1993; Cavigelli, 1999; Harper and Austad, 2000). Application of these techniques demonstrated that certain generally accepted concepts, e.g., a lower stress level in dominants, are not observed in many species, for instance, in certain social predators such as dwarf mongooses $(\mathrm{Hel}$ ogale parvula) and African wild dog (Lycaon pictus) (Creel, 1996). In rodents with deme structure of reproductive groups, males of higher social status and occupying a larger territory have a lower stress level as compared to less successful conspecifics (Moshkin, 2001). Conversely, the number of females in a reproductive group (family) positively correlates with the stress level of the family leader in polygamous species (Rogovin, 2003). Sometimes environmental factors such as habitat type (Marra and Holberton, 1998) or nutritional resources (Moshkin, 2003) considerably affect functional activity of physiological systems of stress in addition to social factors. The above-mentioned examples substantiate comparative study of the role and position of stress in the mechanisms of population control in various mammalian species with different patterns of social structure.

The goal of this work was to study variability of functional activity of the adrenal cortex in males of midday gerbil as a function of intrinsic (population density) and extrinsic (habitat integrity) stress factors.

Midday gerbil is a relatively small representative of the genus Meriones. It prefers open habitats on sandy soils with rare vegetation; it is a typical psammophil and seed-eater (Rall', 1940) largely feeding on the seeds of grasses and ephemerals complemented with 
green stuff in spring and early summer and juicy stem parts in summer (no more than 15-20\% of total diet volume). Midday gerbils usually live solitary and do not form stable family groups; the animals avoid contacts with conspecifics (Popov, 1989). They proved to lack density-dependent inhibition of reproduction; their extermination did not increase the proportion of pregnant females in the population (in contrast to, for instance, tamarisk gerbils) and their numbers were restored through a higher survival rate of young animals (Kuznetsov and Matrosov, 1985). These considerations together with specific social behavior allowed us to assign midday gerbils to socially indifferent species (Popov and Tchabovsky, 1995; Popov and Tchabovsky, in press).

Thus, midday gerbil is clearly interesting for comparative investigation of stress factors active in the natural environment. Here we studied the concentration of corticosterone in the feces of males from local settlements with different population density and food resource integrity. Considering specific social structure of the species, we expected a higher contribution of extrinsic population factors to variability of male adrenocortical activity as compared to intrinsic population ones.

\section{MATERIALS AND METHODS}

The study area. The field material was collected in May-June 2000 in the Southern Kalmykia at the boundary between the Chernozemel'skii and IkiBurul'skii Districts $\left(45^{\circ} 29^{\prime} \mathrm{N}, 45^{\circ} 26^{\prime} \mathrm{E}\right)$ near Achinery (former Chernozemel'sk) Settlement.

The study area is a sub-boreal semidesert with the vegetation composed of ephemerals, annuals, perennial sod grasses, psammophytic herbage, and subshrubs. Demutation processes of local pasture ecosystems in recent decades introduced diverse plant communities representing different stages of restoration succession (Neronov, 2002) or, in other words, habitats with different degrees of integrity.

Marking and recapturing. The experiments were carried out on five standard $100 \times 100 \mathrm{~m}$ (1 hectare) plots. Vegetation status was ranked according to the system proposed by Neronov (1998, 2002). Plots with 0 , below $50 \%$, and above $50 \%$ of disturbed areas (i.e., at the early stages of demutation succession) were considered as undisturbed, little-disturbed, and much disturbed, respectively.

The population density and space utilization indices were evaluated using the method of individual marking and recapturing. The gerbils were captured in Shchipanov's live traps (1987), which were set in the corners of $10 \times 10 \mathrm{~m}$ squares. Sex and age were determined in the captured animals. The details of capturing are described elsewhere (Neronov, 1997).

Population density was determined as a total number of marked adult animals on a plot within 10-14

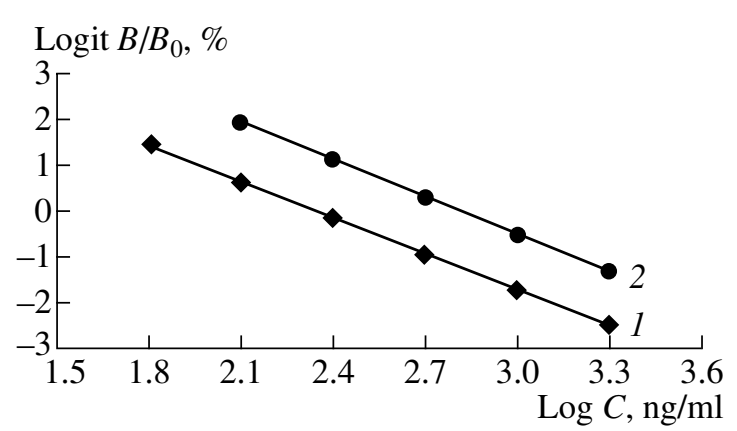

Fig. 1. Binding curves for doubled corticosterone content in the standard (1) and feces samples (2); $y=-2.63 x+6.16(1)$ and $y=-2.71 x+7.62(2)$.

days, since analysis of the dynamics of gerbil capturing on five plots in spring 2000 demonstrated capturing of the whole adult population within 6-8 days. The age limitations were due to nonsynchronous offspring emergence in the settlements during the period of work, which could lead to incorrect abundance estimation in different settlements. We distinguished plots with high (over 40 adults per hectare), medium (20-40), and low (below 20) population densities.

Quantitation of hormones in samples. Feces only from adult males were collected. Exclusion of females from the study was due to, apart from cost saving, wide variations in their endocrine status including adrenal cortex activity as a result of pregnancy and nursing (McDonald, 1998), which consequently complicated getting a homogeneous material for evaluation of stress effects of local density and feeding conditions. The samples were collected during regular inspections of the traps within the intervals of 2-3 h after trap setting. Such interval allows us to avoid the "effect of capture," since the latent time of corticosterone concentration increase in the feces is at least $3 \mathrm{~h}$ after stress stimulus (Harper and Austad, 2001; Zav'yalov, 2003). In total, 113 samples from 49 males were collected.

In order to evaluate corticosterone in the males, the feces collected in the field were dried to constant weight at $30-40^{\circ} \mathrm{C}$. Dry feces samples were homogenized in bidistilled water and centrifuged. Corticosterone was extracted from the supernatant by diethyl ether. The extracts were evaporated and the solid was resuspended in phosphate buffer. Radioimmune assay for corticosterone was carried out according to the instructions for the applied antibodies (Anti-Corticosterone SIGMA). The Student's test for parallelism of the binding curves for feces samples (feces from several males were combined) and regression curves of standard corticosterone revealed no significant differences $(p>$ 0.05) (Fig. 1), which substantiated application of commercial antibodies to determine hormone levels in midday gerbil.

Statistical analysis. Since our data did not conform to the normal distribution assumption, we used both 

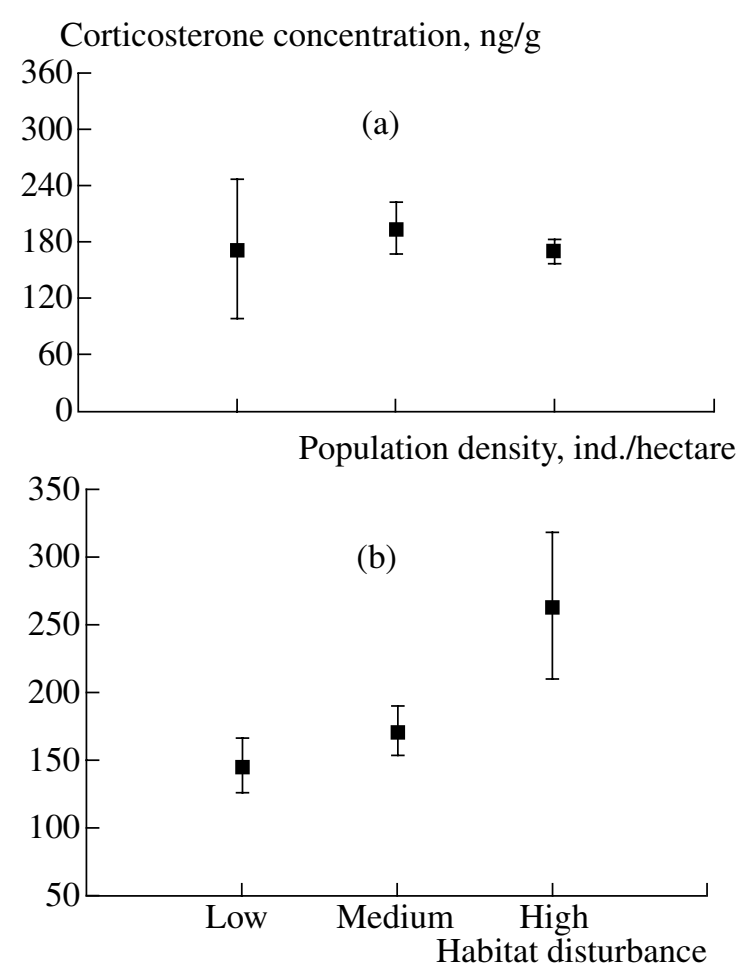

Fig. 2. The level of corticosterone in midday gerbils as a function of population density (a) and habitat integrity (b).

nonparametric (the Kruskal-Wallis ANOVA test) and parametric methods of statistical processing (one-way and two-way ANOVA) for the log-normalized data. Interindividual variability was evaluated using a series of (at least three) samples from each animal. The dependence of the stress level on the habitat type and population density was determined from the first sample for each animal (i.e., the samples of the first capture).

\section{RESULTS}

Corticosterone level in the feces of midday gerbils ranged from 53 to $602 \mathrm{ng} / \mathrm{g}(N=103)$. Reproducibility of individual corticosterone concentrations in a series of feces samples (three and more) was insignificant $\left(F_{10,48}=1.15, p=0.3470\right)$, which indicates high individual variability of adrenocortical activity exceeding the interindividual one. This suggests a strong dependence of adrenocortical activity in male midday gerbils on environmental factors.

Corticosterone level did not significantly differ in animals from settlements with different densities (Fig. 2a, Kruskal-Wallis ANOVA, $\left.\mathrm{H}_{2,40}=0.90, p=0.6368\right)$. In contrast, habitat integrity significantly influenced the stress level: corticosterone level in the animals increased with the disturbance of their habitat (Fig. 2b, Kruskal-Wallis ANOVA, $\mathrm{H}_{2,40}=6.78, p=0.0337$ ).
Since the habitats of different integrity had different population densities as well, we performed a two-way ANOVA (nested design) of adrenocortical activity as a function of habitat integrity (the main factor) with simultaneous test for possible effect of animal population density (nested factor). This analysis demonstrated a significant effect of the integrity factor on the level of corticosterone $\left(F_{1,36}=7.15, p=0.0112\right)$, while the density factor had no considerable contribution to the stress level variability $\left(F_{2,36}=0.24, p=0.7847\right)$.

\section{DISCUSSION}

The obtained data demonstrated that the stress level in midday gerbils from different settlements did not depend on their population density but increased with the disturbance of their habitat. The assumption on intrinsic population mechanisms of density-dependent autoregulation of animal abundance does not always agree with the data obtained for free-living populations. For instance, an inverse relationship between population density and stress level was revealed in a wild population of water vole (Evsikov, 1999). In addition, the absence of the relationship between corticosterone level in midday gerbils and their population density agrees with the data on high social independence of this species (Tchabovsky, 1993; Gol'tsman, 1994; Popov and Tchabovsky, 1995). It is manifested as an arbitrary, symmetric, and unstable pattern of relationships between individuals inhabiting the same territory and as density-independent reproduction (Kuznetsov and Matrosov, 1985). Low reproducibility of individual levels of corticosterone in the feces agrees with these properties of social behavior. The hormones of the hypothalamus-pituitary-adrenal system considerably contribute to formation of spatial-ethological structure of rodents (Shilov, 1977). Hence, stable individual differences in the level of this neuroendocrine system activity typical for rodents with ordered social structure (Bujalska, 1994; Moshkin, 2001; Rogovin, 2003) can be one of mechanisms fixing the position of an individual in a social hierarchy.

Thus, density-dependent mechanisms of stress response seem to have no significant effect on formation and maintenance of population structure in midday gerbils under natural conditions. Apparently, populations of this species have no mechanisms of density autoregulation (based on stress response, genetic, or behavioral mechanisms) described for many other mammalian species. This is confirmed by an extremely wide range of admissible social conditions (Gol'tsman, 1994; Popov and Tchabovsky, 1995), sharp abundance oscillations in natural populations (Rall', 1939; Pavlinov, 1990), and stable reproduction in populations under hyperdense laboratory conditions (Gol'tsman, 1994).

The revealed significant direct relationship between the stress level of midday gerbils and disturbance of 
their habitat is of clear interest. Development of noninvasive methods for evaluation of stress level of animals in free-living populations made it possible to demonstrate similar relationships between glucocorticoid levels and environmental conditions for many mammals and birds (Wingfield and Kitaysky, 2002). Usually availability of nutritional or water resources as well as protective properties of the habitat serve as specific factors of the stress level (Marra and Holberton, 1998). These conditions also differ in habitats with different integrity. Note that the composition of midday gerbil populations in highly disturbed habitats was less stable and was renewed faster as compared to intact habitats (Tchabovsky and Neronov, unpublished data). A similar phenomenon was observed for American redstart in Jamaica (Marra and Holberton, 1998), where "male" (more successful) and "female" (less successful) habitats are recognized. Individuals living in the latter habitats have a more pronounced seasonal variability of corticosterone levels, which increased during unfavorable periods since the "female" habitats give worse opportunities for successful life then. In addition, high level of corticoids in animals from disturbed habitats can reflect higher time expenditures for their feeding activity (Wingfield, 1998). At the same time, the problem of specific contribution of each of the above-mentioned factors to the observed variability remains open.

\section{ACKNOWLEDGMENTS}

We are grateful to L.E. Savinetskaya, N.L. Ovchinnikova, G.A. Bazykin, and D.Yu. Aleksandrov for their help in collection of the material. The work was carried out in the expedition of the Severtsov Institute of Ecology and Evolution directed by S.A. Shilova, who gave every encouragement to the research. We thank the director of the Elista Antiplague Station A.V. Podsvirov and to V.M. Leont'ev for the help in expedition organization. This work was supported by the Russian Foundation for Basic Research (project nos. 02-04-63016 and 04-04-48479) and Federal Program Integration (project no. E-0308).

\section{REFERENCES}

Boonstra, R., Hik, D., Singleton, G.R., and Tinnikov, A., The Impact of Predator-Induced Stress on the Snowshoe Hare Cycle, Ecol. Monographs, 1998, no. 68, 3, pp. 371-394.

Bujaska, G., Gerlinskaya, L., Grika, L., Grum, L., Evsikov, V., and Moshkin, M., Adrenocortical Variability in Life History of Bank Voles, Pol. Ecol. Stud., 1994, vol. 20, no. 3-4, pp. 305-310.

Cavigelli, S.A., Behavioural Patterns Associated with Faecal Cortisol Levels in Free-Ranging Female Ring-Tailed Lemurs, Lemur catta, Animal Behaviour, 1999, vol. 57, no. 4, pp. 935-944.

Tchabovsky, A.V., Comparative Analysis of Social Structure in Three Gerbil Species of the Genus Meriones, Cand. Sc. (Biol.) Dissertation, Moscow, 1993.
Christian, J.J., The Adrenal-Pituitary System and Population Cycles in Mammals, J. Mammal., 1950, vol. 31, no. 1, pp. 241-259.

Christian, J.J. and Davis, D.E., Adrenal Glands in Female Voles (Microtus pennsylvanicus) as Related to Reproduction and Population Size, J. Mammal., 1966, vol. 47, no. 1, pp. 118.

Creel, S., Creel, M.N., and Monfort, S.L., Social Stress and Dominance, Nature, 1996, vol. 379, p. 212.

Evsikov, V.I. and Moshkin, M.P., The Dynamics and Homeostasis in Natural Animal Populations, Sib. Ekol. Zh., 1994, vol. 1, no. 4, pp. 331-346.

Evsikov, V.I., Gerlinskaya, L.A., and Moshkin, M.P., Population Ecology of the Water Vole (Arvicola terrestris L.) in the West Siberia. Communication 3. Stress and reproduction at Different Stages of the Population Cycle, Sib. Ekol. Zh., 1999, no. 1, pp. 79-89.

Gerlinskaya, L.A., Moshkin, M.P., and Evsikov, V.I., Technical Approaches to Evaluation of Stress Level in Wild Animals, Ekologiya, 1993, no. 1, pp. 97-100.

Gol'tsman, M.E., Popov, S.V., Tchabovsky, A.V., and Borisova, N.G., The sociality Syndrome. A Comparative Study of the Behavior Of Gerbils, Zh. Obshch. Biol., 1994, vol. 55, no. 1, pp. 49-69.

Harper, J.M. and Austad, S.N., Fecal Glucocorticoids: A Noninvasive Method of Measuring Adrenal Activity in Wild and Captive Rodents, Physiol. Biochem. Zool., 2000, vol. 73, no. 1, pp. 12-22.

Harper, J.M. and Austad, S.N., Effect of Capture and Season on Fecal Glucocorticoid Levels in Deer Mice (Peromyscus maniculatus) and Red-Backed Voles (Clethrionomys gapperi), Gen، Comp. Endocrinol., 2001, vol. 123, pp. 337-344. Hennessy, M.B., Social Influences on Endocrine Activity in Guinea Pigs, with Comparisons to Findings in Nonhuman Primates, Neurosci. Biobehav. Rev., 1999, vol. 23, no. 5, pp. 687-698.

Kuznetsov, A.A. and Matrosov, A.N., Effect of Extermination on Reproduction and Death Rate of Small Gerbils from the Volga and Urals Sands, Voprosy prirodnoi ochagovosti $i$ epidemiologii osobo opasnykh infektsii (The Problems of Natural Foci and Epidemiology of Extremely Dangerous Infections), Saratov, 1985, pp. 62-67.

Marra, P.P. and Holberton, R.L., Corticosterone Levels as Indicators of Habitat Quality: Effects of Habitat Segregation in a Migratory Bird during the Non-Breeding Season, Oecologia, 1998, vol. 116, no. 1-2, pp. 284-292.

McDonald, I.R., Lee, A.K., Than, K.A., and Martin, R.W., Concentrations of Free Glucocorticoids in Plasma and Mortality in the Australian Bush Rat (Rattus fuscipes Waterhouse), J. Mammal., 1988, vol. 69, pp. 740-748.

Moshkin, M.P., Gerlinskaya, L.A., Zavjalov, E.L., Kolosova, I.E., Rogovin, K.A., and Randall, J.A., Stress and Nutrition in the Wild, Recent Advances in Animal Nutrition in Australia, 2003, vol. 14, pp. 11-22.

Moshkin, M.P., The Role of Stress in the Maintenance of Population Homeostasis in Mammals (by the Example of Rodents), Doctoral (Biol.) Dissertation, Novosibirsk, 1989.

Neronov, V.V., Spatiotemporal Structure of the Biota of Desert Ecosystems in Kalmykia, Magister Dissertation, Moscow State University, 1998.

Neronov, V.V., The Dynamics of Vegetation and Rodent Populations in the Southern Kalmykia under Changing Environ- 
mental Conditions, Cand. Sc. (Biol.) Dissertation, Moscow, 2002. $252 \mathrm{~s}$.

Neronov, V.V., Tchabovsky, A.V., Aleksandrov, D.Yu., and Kasatkin, M.V., Spatial Distribution of Rodents under Conditions of Anthropogenic Dynamics of Vegetation in the South of Kalmykia, Ekologiya, 1997, no. 5, pp. 369-376.

Novikov, E. and Moshkin, M., Sexual Maturation, Adrenocortical Function and Population Density of Red-Backed Vole, Clethrionomys Rutilus (Pall.), Mammalia, 1998, vol. 62, no. 4, pp. 529-540.

Pavlinov, I.Ya., Dubrovskii, Yu.A., Rossolimo, O.L., and Potapova, E.G., Peschanki mirovoi fauny (Gerbils of the World Fauna), Moscow: Nauka, 1990.

Popov, S.V. and Tchabovsky, A.V., Population Density, Social Environment, and Behavior: Possible Mutual Relationships, Ekologiya, populyatsii: struktura i dinamika (Population Ecology: Structure and Dynamics), Moscow, 1995, pp. 183-202.

Popov, S.V., Tchabovsky, A.V., Shilova, S.A., and Shchipanov, N.A., The Mechanisms of Spatial-Ethological Structure of Midday Gerbil Settlements in the Norm and Forced Population Decline, Fauna i ekologiya gryzunov (Fauna and Ecology of Rodents), Moscow: Mosk. Gos. Univ., 1989, vol. 17, pp. 5-58.

Rall', Yu.M., Introduction to Ecology of Midday Gerbils, Pallasiomys meridianus Pall. I. General Notes, Population Dynamics, and Burrow Activity, Vestn. Mikrobiol. Epidemiol. Parazitol., 1939, vol. 17, no. 3-4, pp. 331-363.

Rall', Yu.M., Introduction to Ecology of Midday Gerbils, Pallasiomys meridianus Pall. III. Feeding. Age Patterns.
Lifespan and Death Rate, Vestn. Mikrobiol. Epidemiol. Parazitol., 1940, vol. 18, no. 3-4, pp. 320-358.

Rogovin, K., Randall, J.A., Kolosova, I., and Moshkin, M., Social Correlates of Stress in Adult Males of the Great Gerbil, Rhombomys opimus, in years of High and Low Population Densities, Horm. Behav., 2003, vol. 43, no. 1, pp. 132139.

Rogovin, K.A., Moshkin, M.P., Rendall, J.A., Kolosova, I.E., and Chikin, Yu.A., Environmental Resources, Social Demography, and Stress in Great Gerbil Populations in the Period of Population Decline, Zool. Zh., 2003, vol. 82, no. 4, pp. 497-507.

Shchipanov, N.A., A Universal Live Trap for Small Mammals, Zool. Zh., 1987, vol. 66, no. 5, pp. 759-761.

Shilov, I.A., Ekologo-fiziologicheskie osnovy populyatsionnykh otnoshenii u zhivotnykh (Ecological and Physiological Basis of Population Interactions of Animals), Moscow: Mosk. Gos. Univ., 1977.

Wingfield, J.C. and Kitaysky, A.S., Endocrine Responses to Unpredictable Environmental Events: Stress or Anti-Stress Hormones?, Integrative Comp. Biol., 2002, vol. 42, no. 3, pp. 600-609.

Wingfield, J.C., Maney, D.L., Breuner, C.W., Jacobs, J.D., Lynn, S., Ramenofsky, M., and Richardson, R.D., Ecological Bases of Hormone-Behavior Interactions: The "Emergency Life History Stage”, Am. Zool., 1998, vol. 38, pp. 191-206.

Zav'yalov, E.L., Gerlinskaya, L.A., and Evsikov, V.I., Evaluation of Stress Level in Common Redbacked Vole, Clethrionomys glareolus (Rodentidae, Rodentia), by Corticosterone Level in the Feces, Zool. Zh., 2003, vol. 82, no. 4. pp. 508513. 